as Janus-faced, looking one way towards death and the other towards life. ${ }^{10}$ Survival depends on the relationship between the self-destructive and the life-preserving tendencies. If the former are entirely absent we are not dealing with a suicidal attempt.

\section{Steroid Glaucoma}

In 1954 J. François ${ }^{1}$ pointed out that cortisone drops applied to the eye for the treatment of conjunctivitis increased the intraocular pressure, reduced visual function, and caused optic atrophy. H. Goldmann ${ }^{2}$ brought further cases to our notice in 1962. Unfortunately the problem is still with us.

At a recent meeting of the Ophthalmological Society of the United Kingdom S. J. H. Miller ${ }^{3}$ described six cases of corticosteroid-induced glaucoma, and five of these patients had severe loss of visual field which was permanent. The primary condition for which each patient was treated was episcleritis, atopic eczema, allergic conjunctivitis, pinguecula, vernal catarrh, and sympathetic ophthalmitis. None had a family history of glaucoma so far as was known. All of them complained of intermittent haloes or blurred vision and had considerably raised intraocular pressure. They responded dramatically to cessation of therapy in that the intraocular pressure returned to normal limits with one exception. None of them showed continuing deterioration of the field of vision after cessation of treatment, and indeed one or two showed an improvement ; the severity of the field loss was proportional to the total quantity of steroid given.

In recent years the effects of topical corticosteroids on the fluid dynamics of the eye have received careful study, chiefly by B. Becker ${ }^{4}$ and M. F. Armaly. ${ }^{6-9}$ The topical corticosteroids which have been reported to increase the pressure are cortisone itself, hydrocortisone, betamethasone, and dexamethasone in ascending order of potency. The hypertensive response over a period of four weeks is always greater in eyes with open-angle glaucoma. The rise is not accompanied by signs of congestion and resembles that seen clinically in glaucoma simplex. It has also been found that an individual with apparently normal eyes who has a parent with openangle glaucoma reacts to topical corticosteroids by a rise in pressure greater than that of his contemporary who has no family history, and the rise is comparable in size to that found in a patient with frank glaucoma.

Becker ${ }^{5}$ proposed a genetic hypothesis to explain the difference in response to topical corticosteroids found in a normal eye and in one with open-angle glaucoma. Glaucoma simplex is considered to be a heritable trait and to represent the homozygous recessive state with a frequency of $4 \%$ in the general population. Theoretically the heterozygous state should have a frequency of $32 \%$ and the homozygous dominant $64 \%$. The size of the steroid effect on intraocular pressure divides a series of normal people into two groups: group I with the less response consists of individuals who do not bear the recessive gene, and group II with the

\footnotetext{
1 François, J., Ann. Oculist (Paris), 1954, 187, 805.

Goldman, H., Arch Ophthal., 1962, 68, 621.

Miller, S. J. H., Trans. ophthal. Soc. U.K., 1965, in the press.

4 Becker, B., and Mills, D. W., Arch. ophthal., 1963, 70, 500.

5 and Hahn, K. A., Amer. F. Ophthal., 1964, 57, 543.

Armaly, M. F., Arch. Ophthal., 1963, 70, 482.

ibid., 1963, 70, 492.

- ibid., 1964, 71, 636 .

- Gilston Glaucoma Symposium, 1965, in the press.

" Paterson, G., Trans. ophthal. Soc. U.K., 1965, in the press.
}

greater response consists of individuals having the recessive gene either in the heterozygous or in the homozygous state.

Armaly $^{9}$ has carried this one stage further. Applying $0.1 \%$ dexamethasone 21-phosphate three times daily to the right eye in 80 volunteer subjects, he has defined three significantly different groups by the size of the rise in pressure. Group I showed a low level of response with an average rise of $1.6 \mathrm{~mm}$. and formed $66.2 \%$ of the sample. Group IIa showed an intermediate level of response with an average rise of $10 \mathrm{~mm} . \mathrm{Hg}$; this formed $28.8 \%$ of the sample Group IIb showed a rise of pressure of $16 \mathrm{~mm}$. $\mathrm{Hg}$ or greater, and this group formed $5 \%$ of the sample. These percentages are very close to the theoretically derived figures based on Becker's genetic theory.

G. Paterson ${ }^{10}$ has reported a study on a series of siblings and children of patients known to have glaucoma simplex The results were analysed so as to compare Armaly's figures from a sample of the general population with those taken from a group of people who were known to carry the gene of glaucoma. Theoretically none of these latter patients should be in group I, but should show either an intermediate rise indicating the heterozygous state or a large rise indicating the preclinical stage of glaucoma, the disease being age-dependent. In fact Paterson's figures showed that $33 \%$ of the siblings and $33 \%$ of the children actually fitted into group I.

There are several possible explanations for this divergence from expectation. The total dosage of steroids employed by the two workers was not the same. It may be that the penetrance of the gene is incomplete in some cases or that the heritable trait is not the disease of glaucoma itself but rather the pressure response to corticosteroids. Further investigation is required to resolve this paradox.

Meanwhile the clinical lesson to be learnt from this work is the danger of topical corticosteroids, particularly beta- and dexamethasone, when prescribed for a period longer than a week unless ophthalmic supervision is close. The possibility, however, of using corticosteroid eye drops to detect genetic liability to glaucoma may prove to be of practical value

\section{Electroencephalography in Childhood}

The sudden occurrence of a local lesion in the brain is usually accompanied by a prompt change in the electrical activity of the neighbouring regions. This can be recorded by the electroencephalograph (E.E.G.), though the relation between the lesion of the brain and the concomitant electrical changes is not fully understood. Frequently, however, the E.E.G. record changes continually until the condition has either resolved or become static. ${ }^{1}$

The E.E.G. findings in childhood differ from those in adults, both in normal subjects and in patients with diseases of the brain. For example, the progression of brain tumours in children is considerably different from that of adults, both clinically and electroencephalographically. Similarly, acute lesions of the brain, such as abscesses, various forms of encephalitis, or vascular disorders, also have different features according to the age of the patient. In children the E.E.G. changes are often disproportionately greater than those seen in apparently similar conditions in adults. 
The study of the electrical activity of the brain has played an essential part in the development of our present-day views on epilepsy, though even now very little is known about the mechanisms within the central nervous system that may lead to the appearance of the clinical phenomena which we call epilepsy. We do not understand why a seizure begins, nor why a convulsion stops, nor why particular types of seizures are seen more frequently in some age groups than in others. Yet the E.E.G. features may be correlated with the severity of a disorder in which seizures are a prominent feature. Thus J. A. R. Tibbles and J. S. Prichard ${ }^{2}$ reviewed the value of the E.E.G. for prognosis in neonatal convulsions, studying the initial appearances in relation to the clinical outcome. They found that $70 \%$ of the babies who had a normal E.E.G. developed normally, but that $64 \%$ of those with abnormal E.E.G.s subsequently showed definite neurological sequelae.

Most of the clinical E.E.G. studies on epilepsies have emphasized the descriptive aspects. Paroxysmal disturbances of the electrical patterns of brain activity are usually seen in patients suffering from seizures of cerebral origin, not only during fits but also in between fits when there are apparently no clinical changes. The E.E.G. alterations, whether focal or generalized, may last for only a fraction of a second, or they may persist for several seconds-or even minutes or hours-or they may keep reappearing at frequent intervals. Sometimes this electrical abnormality of the brain may be modified by medical or surgical treatment, but often it persists virtually unchanged.

The E.E.G. cannot be used to classify children suffering from " attacks" into two distinct groups-those with epilepsy and those without-for the variety of findings is great. In the past the terms "cough" and "fever" were often considered as disease processes (undulant fever, consumptive fever, idiopathic fever). We now realize that the term "epilepsy," has no more descriptive importance than the term "fever." Electroencephalography has destroyed the traditional division between primary and secondary epilepsy, and we are now beginning to understand that seizures represent a particular type of physio-pathological response of the body (not only of the brain) to a number of noxious processes.

In children as well as in adults the study of the electrical activity of the brain should not be regarded with any greater veneration than the study of any other function of the body. Like other ancillary methods of investigation in medicine, electroencephalography has precise but limited applications. What we may ask of the E.E.G. in its clinical aspects is to assess how a given patient's brain appears to be working. Are the patterns within the normal range of maturity for the patient's age ? Do the various regions of the brain respond in a normal fashion to various specific stimuli, to neurotropic drugs, or to particular alterations in metabolism ? Are there gross differences in the function of the two cerebral hemispheres or between homologous areas of the brain ? What diseases or conditions could perhaps be considered, or excluded, on the basis of the child's E.E.G. features, and on what margin of reliability? This method of reasoning is applicable to the evaluation of many physical signs in medicine, and electroencephalographic investigations are no exception.

\footnotetext{
Kellaway, P., and Petersén, I., Neurologic and Electroencephalographic Correlative Studies in Infancy, 1964. Grune and Stratton, New York.

Tibbles, J. A. R., and Prichard, J. S., Pediatrics, 1965, 35, 778.
}

\section{Drugs for Bed-wetting}

"Of Pissing in the Bedde" and its treatment Thomas Phaire in The Boke of Chyldren (1553) wrote: "Take the wesande [windpipe] of a cocke, and plucke it, tha brenne it in pouder, and use of it twyse or thryse a daye. The stones of an hedgehogge poudred is of the same vertue." He might even be thought to have foreshadowed the modern electricbuzzer device ${ }^{1}$ when he continued : "If the pacient be of age, it is good to make fyne plates of leade, with holes in them, and let them lye often to the naked backe."

Thus nocturnal enuresis is by no means a new problem, and claims for drugs to treat it are no newer. It might be suspected from their very number, and the speed with which most go out of fashion, that many are " of the same vertue" as the wesande of the cocke.

A group of drugs that is frequently used to treat enuresis at the present time is the antispasmodics, among which belladonna is one of the more popular. Like ephedrine (a sympathomimetic amine) it causes the muscles in the bladder wall to relax and so can increase the capacity of the bladder. But its action is short-lived, perhaps two or three hours, and a single dose in the evening could hardly be effective throughout the night, except through suggestion. Posterior pituitary extract, taken as a snuff, ${ }^{2}$ is open to similar criticism. Amphetamine, a central stimulant, is another popular drug for enuresis. Many children with nocturnal enuresis seem to sleep very deeply, and amphetamine can certainly lighten their sleep. Thus in principle its use should enable them to wake in response to the stimulus of a bladder that is about to empty.

Though their effect on sleep is the opposite of that produced by amphetamine, the transquillizer group of drugs is also employed in the treatment of enuresis. Several recent reports deal with the use of imipramine (Tofranil), which has previously been used to treat depression. S. J. Epstein and F. M. Guilfoyle ${ }^{3}$ treated 10 enuretic children with imipramine and found that there was a prompt improvement, which was maintained in most cases when the drug was stopped after a few weeks. Using the same drug in a double-blind trial A. F. Poussaint and K. S. Ditman ${ }^{4}$ showed that in most cases enuresis was improved, and that in some it was abolished. Nevertheless, they found that larger doses and a longer period of treatment were necessary than those described by Epstein and Guilfoyle. Nearly half of their 47 children were dry after treatment and many of the rest showed considerable improvement; in only $15 \%$ was no improvement noted. There were few unpleasant side-effects. One suggested mode of action is that imipramine relaxes the detrusor muscle of the bladder and increases the tonicity of the vesical outlet, so permitting the bladder to hold more urine before micturition occurs. This does not, however, explain why children with a " small bladder" do not wake at night to micturate, or why some children on imipramine did wake at night, and it may be that the drug has its effect on enuresis by acting as a stimulant on the brain or as an antidepressant. Neither of the articles mentioned contains a full description of the patients' families, though enuresis often " runs in the family," or of their emotional state, and in neither was there more than a short follow-up period for observation.

\footnotetext{
Brit. med. F., 1958, 2, 499.

${ }^{2}$ Marson, F. G. W., ibid., 1955, 1, 1194

${ }^{3}$ Epstein, S. J., and Guilfoyle, F. M., Amer. F. Dis. Child., 1965, 109, 412.

${ }^{4}$ Poussaint, A. F., and Ditiman, K. S., F. Pediat., 1965, 67, 283.

${ }^{5}$ The Child and His Symptoms, Apley, J., and Mac Keith, R., 1962, Blackwell, Oxford.
} 